\title{
Effects of calcium montmorillonite clay and aflatoxin exposure on dry matter intake, milk production, and milk composition
}

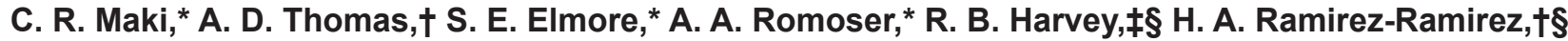 \\ and T. D. Phillips* $\S^{1}$ \\ ${ }^{*}$ College of Veterinary Medicine and Biomedical Sciences, Texas A\&M University, College Station 77843 \\ †Department of Animal Science and Veterinary Technology, Tarleton State University, Stephenville, TX 76402 \\ ¥Food and Feed Safety Research, Agricultural Research Service, USDA, College Station, TX 77845 \\ $\S$ Texas A\&M AgriLife Research, College Station 77843
}

\section{ABSTRACT}

Fifteen primiparous crossbred dairy cows that were $114 \pm 14 \mathrm{~d}$ in milk and weighed $533 \pm 56 \mathrm{~kg}$ were used in a replicated $5 \times 5$ Latin square to test the efficacy of a calcium montmorillonite clay, NovaSil Plus (NSP; BASF Corp., Ludwigshaven, Germany), for the reduction of aflatoxin $(\mathrm{AF})$ metabolite $\left(\mathrm{AFM}_{1}\right)$ in milk and the effect of NSP on milk composition. Cows were housed in a freestall barn, fed once a day and milked twice a day. The experiment consisted of five 14-d periods: $d 1$ through 7 were considered for data collection, and d 8 through 14 were considered a wash-out phase. In each period, cows were randomly assigned to 1 of 5 dietary treatments: (1) control $(\mathrm{CON})$, consisting of a basal total mixed ration (TMR); (2) high-dose NSP diet (NSP-1\%), consisting of TMR plus $230 \mathrm{~g}$ of NSP; (3) aflatoxin diet (AFD), consisting of the TMR plus AF challenge; (4) low-dose NSP with AF (NSP$0.5 \%+\mathrm{AFD})$, composed of TMR plus $115 \mathrm{~g}$ of NSP and AF challenge; and (5) high-dose NSP with AF (NSP$1 \%+\mathrm{AFD})$, consisting of TMR plus $230 \mathrm{~g}$ of NSP and $\mathrm{AF}$ challenge. The AF challenge consisted of top dressing a daily dose of $100 \mu \mathrm{g} / \mathrm{kg}$ estimated dry matter intake (DMI); similarly, NSP was fed at 1.0 or $0.5 \%$ of estimated DMI. Milk yield and DMI were similar across treatments averaging $21.1 \pm 1.33 \mathrm{~kg} / \mathrm{d}$ and $19.7 \pm 0.56$ $\mathrm{kg} / \mathrm{d}$, respectively. Concentration of milk fat, protein, and lactose were similar across treatments with averages of $4.91 \pm 0.20 \%, 3.85 \pm 0.10 \%$, and $4.70 \pm 0.06 \%$, respectively. Concentration of vitamin A averaged $0.28 \pm$ $0.03 \mu \mathrm{g} / \mathrm{mL}$ and riboflavin concentration averaged 1.57 $\pm 0.13 \mu \mathrm{g} / \mathrm{mL}$ across treatments. The concentration of minerals in milk were similar for all treatments. Cows fed CON and NSP-1\% yielded the lowest concentration of $\mathrm{AFM}_{1}$ in milk with 0.03 and $0.01 \pm 0.06 \mu \mathrm{g} / \mathrm{L}$. Addition of NSP reduced milk $\mathrm{AFM}_{1}$ from $1.10 \pm 0.06 \mu \mathrm{g} / \mathrm{L}$

Received August 11, 2015.

Accepted November 4, 2015.

${ }^{1}$ Corresponding author: tphillips@cvm.tamu.edu with the $\mathrm{AF}$ diet to 0.58 and $0.32 \pm 0.06 \mu \mathrm{g} / \mathrm{L}$ with the $\mathrm{NSP}-0.5 \%+\mathrm{AF}$ and NSP-1\%+AF diets, respectively. Excretion of $\mathrm{AFM}_{1}$ was reduced by NSP; mean values were $24.38,11.86,7.38,0.64$, and $0.23, \pm 1.71 \mu \mathrm{g} / \mathrm{d}$, for AFD, NSP-0.5\%+AFD, NSP-1\%+AFD, NSP-1\%, and $\mathrm{CON}$, respectively. More specifically, $1.07 \pm 0.08 \%$ of the daily AF intake was transferred to the milk of cows consuming the AFD, whereas the AF transfer rates in milk from cows that consumed the NSP-0.5\%+AFD and NSP-1\%+AFD were 0.52 and $0.32 \pm 0.08 \%$. Results from this research demonstrate that feeding NSP to lactating cows is an effective method to reduce the transfer and excretion of $\mathrm{AFM}_{1}$ in milk with no negative effects on dry matter intake, milk production, and composition.

Key words: aflatoxin, food safety, milk vitamins, mycotoxins

\section{INTRODUCTION}

Aflatoxins (AF) are harmful secondary metabolites produced primarily by the fungi Aspergillus flavus and Aspergillus parasiticus (Kurtzman et al., 1987). These compounds and their derivatives are known to be immunosuppressive and carcinogenic in different species (Linsell and Peers, 1977; Peers et al., 1987). Feed contamination with AF may originate from pre- and postharvest contamination of crops or feeds. Pre-harvest contamination becomes more prevalent in periods of drought stress and high temperatures during the growing season of crops (Cotty and Jaime-Garcia, 2007), whereas postharvesting contamination may arise from storage conditions that promote fungal growth (Cavallarin et al., 2011).

When AF-contaminated diets are fed to lactating animals, the toxin is primarily metabolized in the liver into a hydroxylated derivative called $\mathrm{AFM}_{1}$ (Kuilman et al., 1998), transported to the mammary gland via blood, and transferred to milk. Detection of $\mathrm{AFM}_{1}$ may occur in periods as short as 5 min postingestion in plasma (Gallo et al., 2008) and $1 \mathrm{~h}$ in milk (Bat- 
tacone et al., 2012). Because of its carcinogenic and toxic properties, the US Food and Drug Administration (FDA, 2000) has set an action level of $0.5 \mu \mathrm{g} / \mathrm{L}$ for $\mathrm{AFM}_{1}$ in milk. Recent drought conditions in the United States have led to greater risk for preharvest AF contamination of crops destined for animal feed (Cotty and Jaime-Garcia, 2007; Guo et al., 2008); therefore, it is necessary to evaluate practical and inexpensive strategies to mitigate AF content in animal feed and animal products. Examples of feed additives that have been reported to decrease the bioavailability of $\mathrm{AF}$ from contaminated dairy rations include yeast-derived products (Firmin et al., 2011), clays such as $\mathrm{Na}$ and $\mathrm{Ca}$ bentonite (Diaz et al., 2004), or combinations of yeast products with clay (Kissell et al., 2013; Xiong et al., 2015). Of these products, montmorillonite clays have yielded the best results, particularly a hydrated calcium montmorillonite available under the trade name NovaSil and NovaSil Plus (NSP; Phillips et al., 1988; Harvey et al., 1991; Phillips et al., 2008, 2002; Kutz et al., 2009).

Effective feed additives must reduce the bioavailability of $\mathrm{AF}$ with no effects on animal performance nor the nutritional content of animal products. Although several studies have reported milk composition from cows consuming AF-contaminated diets, to this date, we are not aware of any experiments where milk vitamins and minerals (nutrient and nonnutrient) were evaluated during $\mathrm{AF}$ challenge and supplementation with NSP. Therefore, the objective of this study was to evaluate the effect of $\mathrm{AF}$ consumption in concert with dietary supplementation with NSP to reduce $\mathrm{AFM}_{1}$ concentrations in milk and to determine responses on milk composition.

\section{MATERIALS AND METHODS}

\section{Animal Care, Housing, and Feeding}

The experimental cows were cared for according to the guidelines stipulated by the Institutional Animal Care and Use Committee of Tarleton State University (Stephenville, TX). Cows were housed in a freestall barn equipped with individual feeding gates (Calan Broadbent Feeding System, American Calan, Northwood, NH). Daily care involved milking at 0900 and $1900 \mathrm{~h}$, individual feeding at $0700 \mathrm{~h}$ for approximately $110 \%$ ad libitum consumption, and orts were collected, weighed, and recorded individually. The experiment consisted of five 14-d periods in which d 1 through 7 of each period were considered for data collection and d 8 through 14 were considered a wash-out period to avoid carry-over effects. Body weight and BCS (1 to 5 scale) were measured on d 6 and 7 of each period after milking; the scoring method used was similar to that of Wildman et al. (1982), but reported to the quarter point. Body condition score was independently measured by 2 evaluators, and scores were averaged.

\section{Animals, Experimental Design, and Treatments}

Fifteen crossbred $($ Holstein $\times$ Jersey $\times$ Norwegian Red $)$ primiparous dairy cows averaging $( \pm \mathrm{SD}) 114 \pm$ 14 DIM and $533 \pm 56 \mathrm{~kg}$ of BW were used in replicated $5 \times 5$ Latin squares. The test product was a calcium montmorillonite clay available under the trade name NovaSil Plus (BASF Corporation, Ludwigshafen, Germany). It was predicted that cows would consume $23 \mathrm{~kg}$ of DM; therefore, NSP was fed at low and high doses equivalent to 0.5 and $1.0 \%$ of predicted DMI; similarly, an AF challenge was carried out by feeding a daily dose of $100 \mu \mathrm{g} / \mathrm{kg}$ estimated DMI via a topdressed supplement. The AF supplement was produced from rice fermentation by A. parasiticus NRRL 2999 as described by Shotwell et al. (1966) and modified by West et al. (1973). Fermented rice was autoclaved and ground and the AF content was initially determined by spectrophotometric analysis (Nabney and Nesbitt, 1965; Wiseman et al., 1967). Rice powder containing $758 \mathrm{mg}$ of $\mathrm{AFB}_{1} / \mathrm{kg}$ of weight was obtained from the Food and Feed Safety Research Facility, USDA/ARS, College Station, TX. The concentration of AF was verified by the Office of The Texas State Chemist, Texas A\&M University (College Station, TX). Of the total $\mathrm{AF}$ content in the rice powder, $79 \%$ was $\mathrm{AFB}_{1}, 16 \%$ was $\mathrm{AFG}_{1}, 4 \%$ was $\mathrm{AFB}_{2}$, and $1 \%$ was $\mathrm{AFG}_{2}$. In each 14-d period, cows within a square were randomly assigned to 1 of 5 dietary treatments: (1) control (CON), consisting of a basal TMR (Table 1); (2) high-dose clay diet (NSP-1\%), consisting of basal TMR plus $230 \mathrm{~g}$ of NSP; (3) AF diet (AFD), consisting of the basal TMR plus AF challenge; (4) low-dose clay with AF (NSP$\mathbf{0 . 5 \%}+\mathbf{A F D}$ ), composed of basal TMR plus $115 \mathrm{~g}$ of NSP and AF challenge; or (5) high-dose clay with AF (NSP-1\%+AFD), consisting of basal TMR plus 230 $\mathrm{g}$ of NSP and AF challenge.

\section{Sampling and Data Collection}

Feed Sampling. Samples of the basal TMR were collected on d 6 and 7 of each period and subsequently pooled by period. The Penn State Forage Particle Separator was used to determine TMR particle size distribution as described by Kononoff et al. (2003). Feed samples were dried at $65^{\circ} \mathrm{C}$ in a forced-air oven to determine DM. After determination of DM, samples were ground (1-mm screen; Wiley Mill, Arthur H. Thomas Co., Philadelphia, PA) and stored at room temperature. A subsample of composite TMR was 
Table 1. Ingredient and analyzed chemical composition of basal diet

\begin{tabular}{lc}
\hline Item & Value \\
\hline Dietary ingredient (\% of DM) & \\
Corn silage & 32.0 \\
Alfalfa hay & 3.4 \\
Coastal grass hay & 3.3 \\
Sudan grass baleage & 2.6 \\
Ground corn & 22.5 \\
Beet pulp pellets & 10.8 \\
Cottonseed & 6.0 \\
Concentrate premix ${ }^{1}$ & 19.4 \\
Chemical (\% of DM) & 16.3 \\
CP & 29.7 \\
NDF & 27.4 \\
Starch & 4.8 \\
Ether extract & 44.16 \\
NFC & 6.8 \\
Ash & \\
Particle size distribution ${ }^{3}$ (\% retained in each sieve) & 6.0 \\
$>19.0$ mm & 32.4 \\
19.0-8.0 mm & 20.9 \\
8.0-4.0 mm & 40.7 \\
\hline 4.0 mm & \\
\hline
\end{tabular}

${ }^{1}$ Contained canola meal, soybean meal, corn dried distillers grains, molasses, expeller-cooked soybean meal (SoyPlus, West Central Cooperative, Ralston, IA), calcium salts of fatty acids (EnergII, Virtus Nutrition, LLC, Corcoran, CA), yeast and yeast culture media extracts (Diamond V XP, Diamond V Mills Inc., Cedar Rapids, IA), isopropyl ester of 2-hydroxy-4-methylthiobutanoic acid (MetaSmart Dry, Adisseo, Alpharetta, GA), sodium sesquicarbonate, mineral and vitamin mix, urea, di-calcium phosphate, sodium chloride, magnesium oxide, calcium carbonate, and monensin.

${ }^{2} \mathrm{NFC}$ calculated by difference of $100-(\% \mathrm{NDF}+\% \mathrm{CP}+\%$ ether extract $+\%$ ash).

${ }^{3}$ Measured using the Penn State Particle Separator (Nasco, Fort Atkinson, WI)

analyzed for nutrient composition by an external laboratory (Cumberland Valley Analytical Services, Hagerstown, MD). Analyses included DM (method 930.15; AOAC International, 2000), N (method 990.03; Leco FP-528 Nitrogen Combustion Analyzer, Leco Corp., St. Joseph, MI), NDF (Van Soest et al., 1991), starch (Hall, 2009), ether extract using diethyl ether as the solvent (method 2003.05; AOAC International, 2006), ash (method 942.05; AOAC International, 2000), and phosphorus by inductively coupled plasma (method 985.01; AOAC International, 2000).

Milk Data Collection. Individual milk production was measured and recorded daily; measurements from the first $7 \mathrm{~d}$ of each period were used to evaluate milk production; additionally, milk samples were collected during the morning and night milking of $\mathrm{d} 6$ and 7 . One aliquot of approximately $30 \mathrm{~mL}$ from each milking was preserved using a pellet of 2-bromo-2-nitropropane-1,3 diol at room temperature. Milk samples were analyzed for fat, true protein, lactose, and SNF (AOAC International, 2000) by an external laboratory (Texas DHIA, Canyon, TX), using a B2000 Infrared Analyzer (Bentley Instruments, Chaska, MN). Milk urea nitrogen was determined by the same laboratory using a modified Berthelot reaction concentration using a ChemSpec 150 Analyzer (Bentley Instruments). Yields of milk components were estimated according to milk weight and time of collection.

Additionally, a composite milk sample was obtained for $\mathrm{d} 6$ and 7 by mixing proportional aliquots from each milking. The composite sample from d 6 was analyzed for $\mathrm{AFM}_{1}$ content, and the composite sample from d 7 was analyzed for vitamin content. Aliquots from the first period d 6 were analyzed for mineral concentration. For AF determination, milk samples were processed according to official AOAC International methods. Briefly, samples were warmed to $37^{\circ} \mathrm{C}$, centrifuged for $20 \mathrm{~min}$ at $2,000 \times g$, and defatted. The samples were passed through a coffee filter to remove any residual fat. Then, a $10-\mathrm{mL}$ aliquot of the defatted fraction was passed through an immunoaffinity column (Afla WB, Vicam, Milford, MA) at a steady gravity-controlled flow rate (approximately $1 \mathrm{~mL} / \mathrm{min}$ ). The columns were washed twice with $10 \mathrm{~mL}$ of double distilled, deionized water (MilliQ $18.2 \mathrm{M} \Omega \mathrm{cm}$ ), and eluted with 4 $\mathrm{mL}$ of acetonitrile. Samples were evaporated to dryness under constant nitrogen. Samples were re-suspended in $1 \mathrm{~mL}$ of $1: 1 \mathrm{MeOH} \cdot \mathrm{H}_{2} \mathrm{O}$ solution and analyzed by LC-MS/MS (Waters H-class UPLC-MS/MS with ESI capability) in the positive mode for $\mathrm{AFM}_{1}$ (molecular weight 328 ). The mobile phase consisted of an isocratic gradient of $30 \% \mathrm{H}_{2} \mathrm{O}, 70 \%$ acetonitrile, and $0.1 \%$ formic acid at a flow rate of $0.325 \mathrm{~mL} / \mathrm{min}$. The column temperature and injection volume were $40^{\circ} \mathrm{C}$ and $10 \mu \mathrm{L}$, respectively. The AF standards were purchased from Sigma Chemical Co. (St. Louis, MO). All solvents were obtained from Fisher Scientific (Pittsburgh, PA). The AF levels were quantified with the instrument software (Empower 2, Waters Corporation, Milford, MA). Aflatoxin excretion and AF transfer were calculated based on milk production on the day of collection according to the following equations:

$$
\begin{aligned}
\mathrm{AF} \text { excretion }= & \text { concentration of } \mathrm{AF} \\
& \text { in milk } \times \text { milk yield }, \\
\mathrm{AF} \text { transfer }= & \left(\frac{\mathrm{AF} \text { excretion }}{\mathrm{AF} \text { intake }}\right) \times 100 .
\end{aligned}
$$

Determination of vitamin A was carried out using AOAC official methods (AOAC International, 2000). Briefly, an aliquot of $10 \mathrm{~mL}$ of milk was added to a $150-\mathrm{mL}$ centrifuge tube. Then, $30 \mathrm{~mL}$ of antioxidant solution (1\% pyrogallol) and $5 \mathrm{~mL}$ of saponification solution (10.5 $\mathrm{M}$ potassium hydroxide) were added to the test tubes. Tubes were then capped and swirled briefly 
to mix. The tubes were then placed in a shaking $\mathrm{H}_{2} \mathrm{O}$ bath at $70^{\circ} \mathrm{C}$ set to 60 oscillations/min for $25 \mathrm{~min}$. After mixing, samples were allowed to cool to room temperature and transferred to a $125-\mathrm{mL}$ separatory funnel; complete transfer was ensured by rinsing the centrifuge tubes with $30 \mathrm{~mL}$ of $\mathrm{H}_{2} \mathrm{O}$ into the funnel. Subsequently, $30 \mathrm{~mL}$ of extraction solvent hexane-methylene chloride $(3+1)$ were added into the funnel and gently mixed for 2 min. The aqueous layer was then removed; this last step was performed in triplicate. A $20-\mathrm{mL}$ aliquot was evaporated to dryness under nitrogen and resuspended in $5 \mathrm{~mL}$ of mobile phase. The analysis was performed by HPLC (Waters Corporation). In this protocol, 100 $\mu \mathrm{L}$ of sample were injected in a mobile phase consisting of hexane-isopropyl alcohol $(100+0.25, \mathrm{vol} / \mathrm{vol})$ with a flow rate of $1.5 \pm 0.2 \mathrm{~mL} / \mathrm{min}$ at ambient temperature. Peaks were detected via UV absorbance at $325 \mathrm{~nm}$ with a sensitivity 0.1 AUFS. The column was a $4.6 \mathrm{~mm}$ id $\times$ $15 \mathrm{~cm}$ stainless steel reversed-phase C-18 column with 5 - $\mu \mathrm{m}$ particle size.

Concentration of riboflavin was determined according to official methods (AOAC International, 2000) following the protocol described by Ndaw et al. (2000). Briefly, $50 \mathrm{~mL}$ of $0.1 \mathrm{M}$ hydrochloric acid was added to $5 \mathrm{~mL}$ of milk in a $250-\mathrm{mL}$ conical flask. The samples were autoclaved at $121^{\circ} \mathrm{C}$ for $30 \mathrm{~min}$ and then allowed to cool to room temperature. Subsequently the $\mathrm{pH}$ was adjusted to 4.5 with $2.5 \mathrm{M}$ sodium acetate followed by addition of $100 \mathrm{mg}$ of Takadiastase (Pfaltz \& Bauer, Waterbury, CT). The solution was incubated for $18 \mathrm{~h}$ in an oven at $45^{\circ} \mathrm{C}$. After incubation, the solution was diluted to $100 \mathrm{~mL}$ with $0.01 \mathrm{M} \mathrm{HCl}$ and filtered with a $0.2-\mu \mathrm{m}$ filter. Analysis was performed by HPLC using an injection volume of $50 \mu \mathrm{L}$ of the filtrate at a flow rate of $1 \mathrm{~mL} / \mathrm{min}$. The HPLC system was equipped with a $250 \times 4.6 \mathrm{~mm}$ i.d. reversed phase column with $5-\mu \mathrm{m}$ particle size. The samples were run in isocratic mode using methanol:buffer (30:70) as the mobile phase. The buffer was a $0.5 \mathrm{M}$ sodium acetate solution. Riboflavin was measured directly with fluorescence detection using excitation and emission wavelengths set at 422 and $522 \mathrm{~nm}$, respectively.

For nutrient and nonnutrient mineral analysis in milk, $10-\mathrm{mL}$ aliquots from the first treatment period were analyzed by the Veterinary Integrated Biosciences Metals Analysis Laboratory, College of Veterinary Medicine, Texas A\&M University (College Station) using atomic absorption and inductively coupled plasma mass spectroscopy (ICP-MS; Afriyie-Gyawu et al., 2008). The metals that were analyzed in milk include $\mathrm{Ca}, \mathrm{K}, \mathrm{Mg}, \mathrm{Na}, \mathrm{P}, \mathrm{S}, \mathrm{Ag}, \mathrm{Al}, \mathrm{As}, \mathrm{B}, \mathrm{Ba}, \mathrm{Be}, \mathrm{Cd}$, Co, $\mathrm{Cr}, \mathrm{Cu}, \mathrm{Fe}, \mathrm{Hg}, \mathrm{Li}, \mathrm{Mn}, \mathrm{Mo}, \mathrm{Ni}, \mathrm{Pb}, \mathrm{Sb}, \mathrm{Se}, \mathrm{Sr}, \mathrm{Ti}$, $\mathrm{U}, \mathrm{V}$, and Zn. Briefly, tubes were shaken so that the samples were well mixed. Aliquots were freeze-dried in a Labconco Freezone 12L lyophilizer. Dry milk was powdered and analyzed for $\mathrm{Ag}$ by a direct analysis method employing sample combustion in a stream of oxygen, trapping of $\mathrm{Hg}$ on gold, heating the gold trap to release amalgamated $\mathrm{Hg}$, and analyzing $\mathrm{Hg}(0)$ in the vapor phase by atomic absorption using a Nippon MA-3000 (Nippon Instruments, College Station, TX). All other metals were measured by an aliquot of the powdered sample after digestion with nitric acid, hydrogen peroxide, and hydrochloric acid and then brought to volume with deionized water. Digestate was analyzed for several elements by inductively coupled plasma optical emission spectroscopy using a Spectro CirOS instrument (Fitchburg, MA). Digestate was then diluted by a factor of 10 and analyzed for the remaining 29 elements by ICP-MS using a Perkin Elmer DRC II instrument (Wellesley, MA).

\section{Statistical Analysis}

Data were analyzed as replicated $5 \times 5$ Latin squares using the GLIMMIX procedure of SAS (version 9.3, SAS Institute Inc., Cary, NC). The fixed effects of the model included the square, period within the square, and treatment. Random effects included cow within the square. The linear model for these data is written as follows:

$$
\mathrm{y}_{\mathrm{ijkm}=\mu}+\tau_{\mathrm{m}}+\beta(\tau)_{\mathrm{im}}+\rho(\tau)_{\mathrm{jm}}+\alpha_{\mathrm{k}}+\varepsilon_{\mathrm{ijkm}},
$$

where $y_{\mathrm{ijkm}}$ is the observation $\mathrm{ijkm} ; \mu$ represents the overall mean; $\tau_{m}$ represents the fixed effect square $m$; $\beta(\tau)_{\text {im }}$ represents the random effect of cow i within square $\mathrm{m} ; \rho(\tau)_{\mathrm{jm}}$ represents the fixed effect of period $\mathrm{j}$ within square $\mathrm{m}$; and $\alpha_{\mathrm{k}}$ represents the fixed effect of treatment. The error term $\varepsilon_{\mathrm{ijkm}}$ was assumed to be normally, independently, and identically distributed, with variance $\sigma_{e}^{2}$. Statistical significance for all treatments effects was declared at $P \leq 0.05$; trends are discussed at $P \leq 0.15$. All mean results are presented as least squares means \pm the largest standard error of the mean unless stated otherwise.

\section{RESULTS AND DISCUSSION}

Excretion of $\mathrm{AFM}_{1}$ in bovine milk occurs when cows consume AF-contaminated feedstuffs, particularly grains such as corn and cottonseed. Therefore, prevention of enteric AF absorption is a field-practical and viable strategy to reduce the content of $\mathrm{AFM}_{1}$ in milk. This study investigated the effects of NSP on milk yield and composition of dairy cows fed an AF-contaminated diet. We hypothesized that supplementation with NSP is safe and would reduce $\mathrm{AFM}_{1}$ concentration in milk 
with no effects on lactational performance or milk composition.

Prior to initiation of the study, it was predicted that cows would consume $23 \mathrm{~kg}$ of DM. Consequently, we prepared fixed amounts of AF supplement and NSP doses. The daily dose of $\mathrm{AF}$ was $100 \mu \mathrm{g}$ of $\mathrm{AB}_{1} / \mathrm{kg}$ of DM, and NSP dosages were 115 and $230 \mathrm{~g} / \mathrm{d}$, equivalent to 0.5 and $1.0 \%$ of estimated DMI. Upon completion of the experiment, DMI was similar $(P=0.34$; Table 2) across treatments averaging $19.7 \pm 0.56 \mathrm{~kg}$, which is $3.3 \mathrm{~kg}$ less than anticipated. Therefore, total $\mathrm{AFB}_{1}$ concentration in the TMR was $117 \mu \mathrm{g} / \mathrm{kg}$ and NSP supplementation was at 0.58 and $1.17 \%$ of actual DMI; total intake of $\mathrm{AFB}_{1}$ remained at 2,300 $\mu \mathrm{g} / \mathrm{d}$ across treatments. Our observations on DMI are in accordance with similar studies with dairy cows where daily intake of $\mathrm{AFB}_{1}$ ranged from $1,725 \mu \mathrm{g}$ (Queiroz et al., 2012) to 2,500 $\mu \mathrm{g}$ (Kutz et al., 2009) with no effect on DMI. Milk yield was also similar $(P=0.75)$ across treatments with an average of $21.1 \pm 1.33 \mathrm{~kg} / \mathrm{d}$; Kutz et al. (2009) used a similar sorbent and reported no deleterious effects on milk yield. We observed similar concentrations of fat $(P=0.17)$, protein $(P=0.38)$, and lactose $(P=0.22)$ across all treatments. Overall, milk composition averaged $4.91 \pm 0.20 \%$ fat and 3.85 $\pm 0.10 \%$ protein. This is in accordance with other studies, in which feeding an AF-contaminated diet did not affect milk composition of dairy cows (Kutz et al., 2009; Queiroz et al., 2012), goats (Smith et al., 1994), and ewes (Firmin et al., 2011; Battacone et al., 2012).
Furthermore, vitamin A and riboflavin concentration in milk were similar across treatments and averaged 0.28 \pm 0.03 and $1.57 \pm 0.13 \mu \mathrm{g} / \mathrm{mL}$, respectively. The riboflavin content is within the range reported by Poulsen et al. (2015), $1.93 \mu \mathrm{g} / \mathrm{mL}$ for Danish Jersey and 1.40 $\mu \mathrm{g} / \mathrm{mL}$ for Danish Holstein. Also, the concentrations of all minerals analyzed in milk samples were similar across all treatment groups (Table 3). Based on these findings, data from the first period were taken as representative of mineral concentration throughout the study. We are not aware of similar studies in which responses in milk vitamins or minerals were evaluated during AF challenge and supplementation with NSP; therefore, this is the first report to confirm no interference with nutritional vitamins and minerals in milk due to NSP inclusion in the diet.

Data of $\mathrm{AFM}_{1}$ content in milk are presented in Table 4 and Figure 1; we observed a dose-dependent reduction $(P<0.01)$ in concentration of $\mathrm{AFM}_{1}$ in milk with the inclusion of NSP. Feeding AFD resulted in $1.10 \pm$ $0.06 \mu \mathrm{g} / \mathrm{L}$; this value was reduced by $47.3 \%(0.58 \pm$ $0.06 \mu \mathrm{g} / \mathrm{L}$ ) with the inclusion of NSP at $0.58 \%$ of DMI and by $70.9 \%(0.32 \pm 0.06 \mu \mathrm{g} / \mathrm{L})$ when NSP was fed at $1.17 \%$ of DMI. Similarly, Kutz et al. (2009) reported a $48 \%$ reduction in milk $\mathrm{AFM}_{1}$ when feeding NSP at $0.56 \%$ of DMI. Novasil Plus has been reported to effectively adsorb $\mathrm{AFB}_{1}$ in laboratory conditions at $\mathrm{pH} 6.5$ (Marroquín-Cardona et al., 2011). Interestingly, this $\mathrm{pH}$ is close to the mean rumen $\mathrm{pH}$ observed in dairy cows; therefore, the reduction $(P<0.01)$ in AF transfer

Table 2. Effect of dietary addition of NovaSil Plus ${ }^{1}$ on the performance of dairy cows consuming an aflatoxin (AF)-challenge diet

\begin{tabular}{|c|c|c|c|c|c|c|c|}
\hline Item & \multicolumn{5}{|c|}{ Dietary treatment ${ }^{2}$} & $\mathrm{SEM}^{3}$ & $P$-value ${ }^{4}$ \\
\hline DMI (kg/d) & 20.00 & 19.40 & 19.80 & 19.90 & 19.30 & 0.56 & 0.34 \\
\hline $3.5 \% \mathrm{FCM}^{5}$ & 25.30 & 25.50 & 25.30 & 24.90 & 24.50 & 1.50 & 0.88 \\
\hline Fat $(\%)$ & 5.01 & 5.04 & 4.80 & 4.76 & 4.92 & 0.20 & 0.17 \\
\hline Fat yield $(\mathrm{kg} / \mathrm{d})$ & 1.01 & 1.02 & 1.00 & 0.97 & 0.97 & 0.06 & 0.74 \\
\hline SNF $(\%)$ & 9.72 & 9.60 & 9.68 & 9.56 & 9.66 & 0.13 & 0.44 \\
\hline Lactose $(\%)$ & 4.77 & 4.61 & 4.72 & 4.67 & 4.73 & 0.08 & 0.22 \\
\hline Lactose yield $(\mathrm{kg} / \mathrm{d})$ & 0.99 & 0.96 & 1.00 & 0.99 & 0.96 & 0.07 & 0.89 \\
\hline Vitamin A $(\mu \mathrm{g} / \mathrm{mL})$ & 0.28 & 0.27 & 0.28 & 0.28 & 0.29 & 0.03 & 0.91 \\
\hline Riboflavin $(\mu \mathrm{g} / \mathrm{mL})$ & 1.67 & 1.57 & 1.59 & 1.51 & 1.52 & 0.13 & 0.87 \\
\hline MUN (mg/dL) & 11.66 & 12.02 & 11.24 & 10.74 & 11.20 & 1.13 & 0.29 \\
\hline $\mathrm{BW}(\mathrm{kg})$ & 541.00 & 540.00 & 543.00 & 538.00 & 541.00 & 13.69 & 0.79 \\
\hline
\end{tabular}

\footnotetext{
${ }^{1}$ NovaSil Plus (BASF Corp., Ludwigshaven, Germany) is a calcium montmorillonite clay.

${ }^{2} \mathrm{CON}=$ basal TMR; NSP-1 $\%=$ basal TMR $+230 \mathrm{~g}$ of clay; AFD $=$ basal TMR $+117 \mu \mathrm{g}$ of AFB $1 / \mathrm{kg}$ of DMI; NSP-0.5\% + AFD $=$ basal TMR $+115 \mathrm{~g}$ of clay $+117 \mu \mathrm{g}$ of $\mathrm{AFB}_{1} / \mathrm{kg}$ per $\mathrm{d}$ of DMI; NSP-1\%+AFD = basal TMR $+230 \mathrm{~g}$ of clay $+117 \mu \mathrm{g}$ of $\mathrm{AFB}{ }_{1} / \mathrm{kg}$ of DMI.

${ }^{3}$ Highest standard error of treatment mean is shown.

${ }^{4}$ Main effect of treatment.

${ }^{5} 3.5 \% \mathrm{FCM}=[$ milk fat $(\mathrm{kg}) \times 16.216]+[$ milk yield $(\mathrm{kg}) \times 0.4324]$.

${ }^{6} 1-5$ scale (Wildman et al., 1982).
} 
Table 3. Effect of dietary addition of NovaSil Plus ${ }^{1}$ on nutrient and nonnutrient minerals in milk of dairy cows consuming an aflatoxin (AF)challenge diet

\begin{tabular}{|c|c|c|c|c|c|c|c|}
\hline \multirow[b]{2}{*}{$\begin{array}{l}\text { Mineral } \\
(\mathrm{mg} / \mathrm{kg} \text { per } \mathrm{dw})^{2}\end{array}$} & \multicolumn{5}{|c|}{ Dietary treatment ${ }^{3}$} & \multirow[b]{2}{*}{$\mathrm{SEM}^{4}$} & \multirow[b]{2}{*}{$P$-value ${ }^{5}$} \\
\hline & $\mathrm{CON}$ & NSP-1\% & $\mathrm{AFD}$ & $\begin{array}{c}\text { NSP- } \\
0.5 \%+\mathrm{AFD}\end{array}$ & $\begin{array}{c}\text { NSP- } \\
1 \%+\mathrm{AFD}\end{array}$ & & \\
\hline $\mathrm{Ca}$ & $6,746.67$ & $7,296.67$ & $7,410.00$ & $7,166.67$ & $7,680.00$ & $1,013.40$ & 0.95 \\
\hline K & $7,890.00$ & $8,310.00$ & $8,603.33$ & $9,010.00$ & $8,863.33$ & $1,099.10$ & 0.81 \\
\hline $\mathrm{Mg}$ & 781.33 & 774.00 & 726.00 & 844.33 & 808.00 & 104.09 & 0.78 \\
\hline $\mathrm{Na}$ & $2,360.00$ & $2,166.67$ & $2,463.33$ & $2,830.00$ & $2,603.33$ & 479.80 & 0.67 \\
\hline $\mathrm{Ag}$ & $<0.01$ & $<0.01$ & $<0.01$ & $<0.01$ & $<0.01$ & $5.6 \mathrm{e}^{-4}$ & 0.85 \\
\hline $\mathrm{Al}$ & $<0.98$ & $<1.01$ & $<0.97$ & $<0.97$ & $<0.99$ & $5.6 \mathrm{e}^{-2}$ & 0.85 \\
\hline As & $<0.10$ & $<0.10$ & $<0.10$ & $<0.10$ & $<0.10$ & $5.6 \mathrm{e}^{-3}$ & 0.85 \\
\hline B & 0.70 & 0.95 & 0.90 & 0.93 & 0.82 & 0.22 & 0.72 \\
\hline $\mathrm{Ba}$ & 0.47 & 0.63 & 0.56 & 0.48 & 0.60 & 0.13 & 0.30 \\
\hline $\mathrm{Be}$ & $<0.05$ & $<0.05$ & $<0.05$ & $<0.05$ & $<0.05$ & $2.7 \mathrm{e}^{-3}$ & 0.85 \\
\hline $\mathrm{Cd}$ & $<0.01$ & $<0.01$ & $<0.01$ & $<0.01$ & $<0.01$ & $5.6 \mathrm{e}^{-4}$ & 0.86 \\
\hline $\mathrm{Li}$ & $<0.20$ & $<0.20$ & $<0.19$ & $<0.19$ & $<0.20$ & 0.01 & 0.85 \\
\hline $\mathrm{Mn}$ & 0.15 & 0.17 & 0.17 & 0.16 & 0.19 & 0.05 & 0.94 \\
\hline Mo & 0.31 & 0.33 & 0.32 & 0.35 & 0.33 & 0.05 & 0.92 \\
\hline $\mathrm{Ni}$ & $<0.10$ & $<0.10$ & $<0.10$ & $<0.10$ & $<0.10$ & $5.6 \mathrm{e}^{-3}$ & 0.85 \\
\hline $\mathrm{Pb}$ & $<0.05$ & $<0.05$ & $<0.05$ & $<0.05$ & $<0.05$ & $2.7 \mathrm{e}^{-5}$ & 0.85 \\
\hline $\mathrm{Sb}$ & $<0.01$ & $<0.01$ & $<0.01$ & $<0.01$ & $<0.01$ & $3.8 \mathrm{e}^{-3}$ & 0.72 \\
\hline $\mathrm{Se}$ & 0.43 & 0.47 & 0.46 & 0.42 & 0.45 & 0.04 & 0.73 \\
\hline $\mathrm{Sr}$ & 3.13 & 5.43 & 3.35 & 3.37 & 5.43 & 1.00 & 0.07 \\
\hline $\mathrm{Ti}$ & $<0.01$ & $<0.01$ & $<0.02$ & $<0.01$ & $<0.01$ & $6.7 \mathrm{e}^{-3}$ & 0.50 \\
\hline $\mathrm{U}$ & $<0.01$ & $<0.01$ & $<0.01$ & $<0.01$ & $<0.01$ & $1.6 \mathrm{e}^{-3}$ & 0.62 \\
\hline $\mathrm{V}$ & $<0.05$ & $<0.05$ & $<0.05$ & $<0.08$ & $<0.05$ & $2.7 \mathrm{e}^{-3}$ & 0.85 \\
\hline Zn & 30.57 & 35.57 & 35.87 & 27.40 & 32.93 & 3.77 & 0.13 \\
\hline
\end{tabular}

${ }^{1}$ NovaSil Plus (BASF Corp., Ludwigshaven, Germany) is a calcium montmorillonite clay.

${ }^{2}$ Dry weight $(\mathrm{dw})$ of freeze-dried milk powder.

${ }^{3} \mathrm{CON}=$ basal TMR; NSP- $1 \%=$ basal TMR $+230 \mathrm{~g}$ of clay; $\mathrm{AFD}=$ basal TMR $+117 \mu \mathrm{g}$ of $\mathrm{AFB} / \mathrm{kg}$ of DMI; NSP-0.5\% $+\mathrm{AFD}=$ basal TMR $+115 \mathrm{~g}$ of clay $+117 \mu \mathrm{g}$ of $\mathrm{AFB}_{1} / \mathrm{kg}$ per $\mathrm{d}$ of DMI; NSP-1\%+AFD $=$ basal TMR $+230 \mathrm{~g}$ of clay $+117 \mu \mathrm{g}$ of $\mathrm{AFB} / \mathrm{kg}$ of DMI.

${ }^{4}$ Highest standard error of treatment mean is shown.

${ }^{5}$ Main effect of treatment.

in this experiment may be explained by adsorption of $\mathrm{AF}$ in the rumen, thus rendering the toxin unavailable for absorption in the lower gastrointestinal tract. Specifically, transfer rate was reduced from $1.07 \%$ with the
AF diet to $0.52 \%$ and $0.32 \pm 0.08 \%$ with the inclusion of NSP at $0.58 \%$ and $1.17 \%$ of DMI. Similar transfer rates have been reported for dairy cows consuming AFcontaminated diets (Harvey et al., 1991; Xiong et al.,

Table 4. Effect of dietary addition of NovaSil Plus ${ }^{1}$ on aflatoxin (AF) $\mathrm{M}_{1}$ content in milk from dairy cows consuming an AF-challenge diet

\begin{tabular}{|c|c|c|c|c|c|c|c|}
\hline Item & \multicolumn{5}{|c|}{ Dietary treatment ${ }^{2}$} & $\mathrm{SEM}^{3}$ & $P$-value ${ }^{4}$ \\
\hline$\overline{\mathrm{AFM}_{1}(\mu \mathrm{g} / \mathrm{L})}$ & $0.03^{\mathrm{d}}$ & $0.01^{\mathrm{d}}$ & $1.10^{\mathrm{a}}$ & $0.58^{\mathrm{b}}$ & $0.32^{\mathrm{c}}$ & 0.06 & $<0.01$ \\
\hline Transfer $(\%)$ & NA & $\mathrm{NA}$ & $1.07^{\mathrm{a}}$ & $0.52^{\mathrm{b}}$ & $0.32^{\mathrm{b}}$ & 0.08 & $<0.01$ \\
\hline
\end{tabular}

${ }^{\mathrm{a}-\mathrm{d}}$ Values in the same row with different superscripts differ.

${ }^{1}$ NovaSil Plus (BASF Corp., Ludwigshaven, Germany) is a calcium montmorillonite clay.

${ }^{2} \mathrm{CON}=$ basal TMR; $\mathrm{NSP}-1 \%=$ basal TMR $+230 \mathrm{~g}$ of clay; $\mathrm{AFD}=$ basal TMR $+117 \mu \mathrm{g}$ of $\mathrm{AFB}_{1} / \mathrm{kg}$ of DMI; NSP-0.5\%+AFD = basal TMR $+115 \mathrm{~g}$ of clay $+117 \mu \mathrm{g}$ of $\mathrm{AFB}_{1} / \mathrm{kg}$ per $\mathrm{d}$ of DMI; NSP-1\%+AFD = basal TMR $+230 \mathrm{~g}$ of clay $+117 \mu \mathrm{g}$ of $\mathrm{AFB} / \mathrm{kg}$ of DM.

${ }^{3}$ Highest standard error of treatment mean is shown.

${ }^{4}$ Main effect of treatment. 


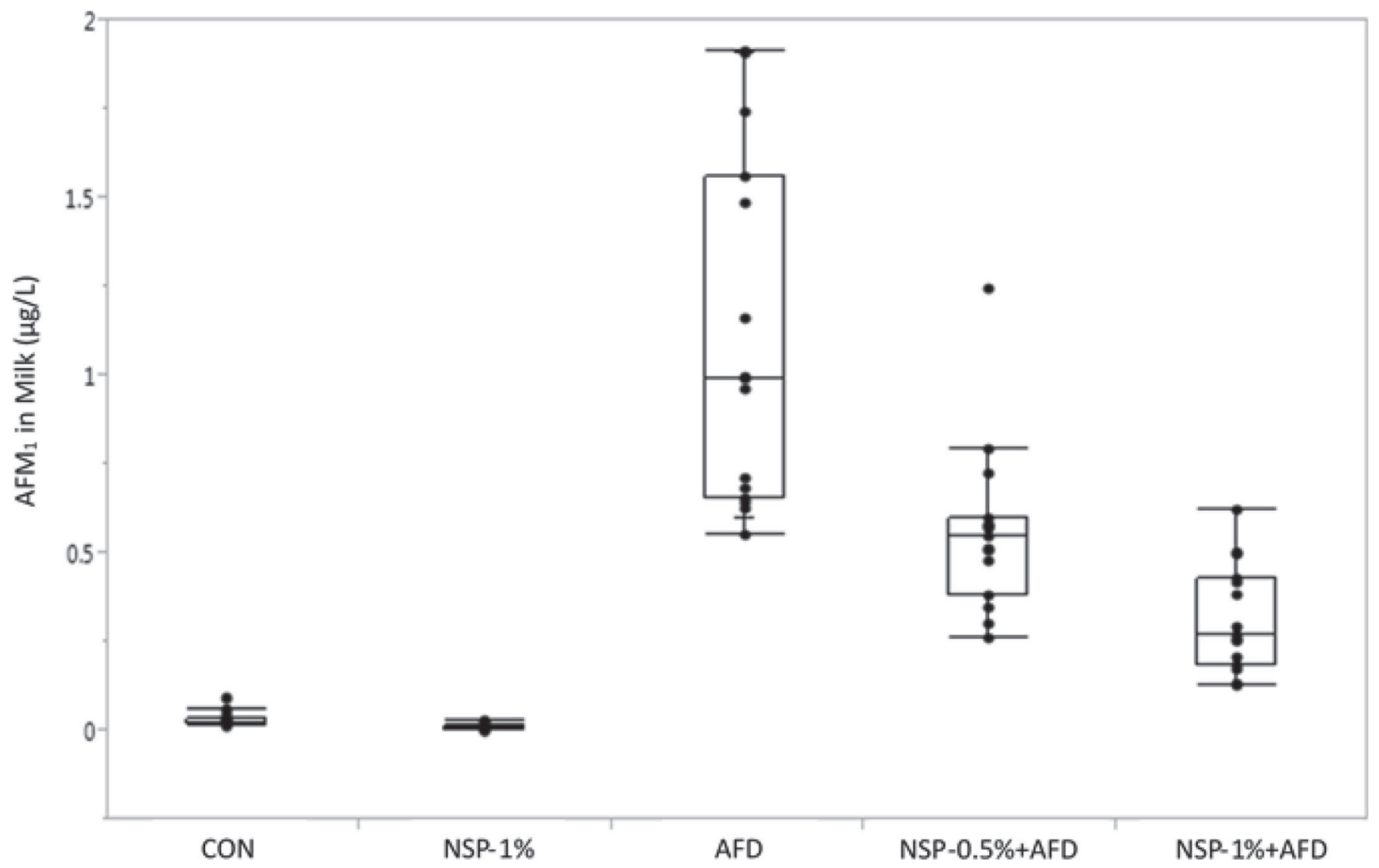

Figure 1. Boxplot representing the interquartile range and distribution of the data from 15 cows sampled at independent time frames in the Latin square design. CON = basal TMR; NSP- $1 \%=$ basal TMR $+230 \mathrm{~g}$ of clay; AFD = basal TMR $+117 \mu \mathrm{g}$ of aflatoxin $(\mathrm{AF}) \mathrm{B} / \mathrm{kg}$ of DMI; $\mathrm{NSP}-0.5 \%+\mathrm{AFD}=$ basal TMR $+115 \mathrm{~g}$ of clay $+117 \mu \mathrm{g}$ of $\mathrm{AFB}_{1} / \mathrm{kg}$ per $\mathrm{d}$ of DMI $\mathrm{NSP}-1 \%+\mathrm{AFD}=\mathrm{basal}$ TMR $+230 \mathrm{~g}$ of clay $+117 \mu \mathrm{g}$ of $\mathrm{AFB}_{1} / \mathrm{kg}$ of DMI. Boxes represent the interquartile range (IQR) between first and third quartiles and the line inside represents the median. The whiskers denote the lowest and highest values within $1.5 \times \mathrm{IQR}$ from the first and third quartiles, respectively. Dots represent data points and outliers beyond the whiskers.

2015). Because of reduced transfer rate, total excretion of $\mathrm{AFM}_{1}$ was also reduced $(P<0.01)$ in a dose-dependent manner. Cows that consumed AFD excreted 24.38 $\mu \mathrm{g} / \mathrm{d}$, whereas cows consuming the NSP-0.5\%+AFD and NSP-1\%+AFD excreted $11.86 \mu \mathrm{g} / \mathrm{d}$ and $7.38 \pm$ $1.71 \mu \mathrm{g} / \mathrm{d}$, which was equivalent to $51.3 \%$ and $69.7 \%$ reduction, respectively. It is important to note that the cows in this study were given diets contaminated with $117 \mu \mathrm{g} / \mathrm{kg}$. This level is more than 5 times the US FDA regulatory standard of $20 \mu \mathrm{g} / \mathrm{kg}$. Dairy feeds are expected to contain $\mathrm{AFB}_{1}$ at levels less than $100 \mu \mathrm{g} /$ $\mathrm{kg}$. At these levels, assuming a $1 \%$ average carry-over of $\mathrm{AF}$, the concentration of $\mathrm{AFM}_{1}$ in milk should fall below the FDA action level of $0.5 \mu \mathrm{g} / \mathrm{L}$. It is also noteworthy that background levels of $\mathrm{AFM}_{1}$ were detected, even in milk from cows consuming the control diet. This finding confirms the presence of naturally occurring $\mathrm{AF}$ in the basal TMR and indicates a need for economically feasible and practical strategies to mitigate this toxin in milk. In future studies, we intend to investigate the ability of NSP to reduce other AF biomarkers in milk.

\section{CONCLUSIONS}

Feed contamination with AF is of special concern in dairy animals due to the inherent risk of increased $\mathrm{AFM}_{1}$ in dairy products intended for human consumption. Our data demonstrate that feeding NSP at 0.58 and $1.17 \%$ of DMI is a safe and effective strategy to reduce concentration and excretion of $\mathrm{AFM}_{1}$ in milk, with no deleterious effects on milk production and composition including vitamin $\mathrm{A}$, riboflavin, and mineral content.

\section{ACKNOWLEDGMENTS}

This work was supported by funding through the Aflatoxin Mitigation Center of Excellence Research Pro- 
gram (National Corn Growers Association, St. Louis, MO), M1403049.

\section{REFERENCES}

Afriyie-Gyawu, E., Z. Wang, N.-A. Ankrah, L. Xu, N. M. Johnson, L. Tang, H. Guan, H. J. Huebner, P. E. Jolly, W. O. Ellis, R. Taylor, B. Brattin, D. Ofori-Adjei, J. H. Williams, J.-S. Wang, and T. D. Phillips. 2008. NovaSil clay does not affect the concentrations of vitamins $\mathrm{A}$ and $\mathrm{E}$ and nutrient minerals in serum samples from Ghanaians at high risk for aflatoxicosis. Food Addit. Contam. Part A Anal. Control Expo. Risk Assess. 25:872-884.

AOAC International. 2000. Official Methods of Analysis. 17th ed. AOAC Int., Arlington, VA.

AOAC International. 2006. Official Methods of Analysis. 18th ed. AOAC Int., Arlington, VA.

Battacone, G., A. Nudda, S. P. G. Rassu, M. Decandia, and G. Pulina. 2012. Excretion pattern of aflatoxin $\mathrm{M}_{1}$ in milk of goats fed a single dose of aflatoxin $B_{1}$. J. Dairy Sci. 95:2656-2661.

Cavallarin, L., E. Tabacco, S. Antoniazzi, and G. Borreani. 2011. Aflatoxin accumulation in whole crop maize silage as a result of aerobic exposure. J. Sci. Food Agric. 91:2419-2425.

Cotty, P. J., and R. Jaime-Garcia. 2007. Influences of climate on aflatoxin producing fungi and aflatoxin contamination. Int. J. Food Microbiol. 119:109-115.

Diaz, D. E., W. M. Hagler Jr., J. T. Blackwelder, J. A. Eve, B. A Hopkins, K. L. Anderson, F. T. Jones, and L. W. Whitlow. 2004 Aflatoxin binders II: Reduction of aflatoxin $\mathrm{M}_{1}$ in milk by sequestering agents of cows consuming aflatoxin in feed. Mycopathologia 157:233-241.

Firmin, S., D. P. Morgavi, A. Yiannikouris, and H. Boudra. 2011. Effectiveness of modified yeast cell wall extracts to reduce aflatoxin B1 absorption in dairy ewes. J. Dairy Sci. 94:5611-5619.

Food and Drug Administration (FDA). 2000. Guidance for industry: Action levels for poisons and deleterious substances in human food and animal feed. Accessed Jul. 31, 2015. http://www.fda.gov/Food/ GuidanceRegulation/GuidanceDocumentsRegulatoryInformation/ ChemicalContaminantsMetalsNaturalToxinsPesticides / ucm077969.htm

Gallo, A., M. Moschini, and F. Masoero. 2008. Aflatoxins absorption in the gastro-intestinal tract and in the vaginal mucosa in lactating dairy cows. Ital. J. Anim. Sci. 7:53-63.

Guo, B., Z. Y. Chen, R. D. Lee, and B. T. Scully. 2008. Drought stress and preharvest aflatoxin contamination in agricultural commodity: Genetics, genomics and proteomics. J. Integr. Plant Biol. 50:1281-1291

Hall, M. B. 2009. Analysis of starch, including maltooligosaccharides, in animal feeds: A comparison of methods and a recommended method for AOAC collaborative study. J. AOAC Int. 92:42-49.

Harvey, R. B., T. D. Phillips, J. A. Ellis, L. F. Kubena, W. E. Huff, and H. D. Petersen. 1991. Effects of aflatoxin M1 residues in milk by addition of hydrated sodium calcium aluminosilicate to aflatoxincontaminated diets of dairy cows. Am. J. Vet. Res. 52:1556-1559.

Kissell, L., S. Davison, B. A. Hopkins, G. W. Smith, and L. W. Whitlow. 2013. Effects of experimental feed additives on aflatoxin in milk of dairy cows fed aflatoxin-contaminated diets. J. Anim. Physiol. Anim. Nutr. (Berl.) 97:694-700.

Kononoff, P. J., A. J. Heinrichs, and D. R. Buckmaster. 2003. Modification of the Penn State forage and total mixed ration particle separator and the effects of moisture content on its measurements. J. Dairy Sci. 86:1858-1863.

Kuilman, M. E. M., R. F. M. Maas, D. J. Judah, and J. Fink-Gremmels. 1998. Bovine hepatic metabolism of aflatoxin $\mathrm{B}_{1}$. J. Agric. Food Chem. 46:2707-2713.

Kurtzman, C. P., B. W. Horn, and C. W. Hesseltine. 1987. Aspergillus nomius, a new aflatoxin-producing species related to $A s-$ pergillus flavus and Aspergillus tamari. Antonie van Leeuwenhoek $53: 147-158$.

Kutz, R. E., J. D. Sampson, L. B. Pompeu, D. R. Ledoux, J. N. Spain, M. Vázquez-Añón, and G. E. Rottinghaus. 2009. Efficacy of Solis, NovasilPlus, and MTB-100 to reduce aflatoxin $\mathrm{M}_{1}$ levels in milk of early to mid lactation dairy cows fed aflatoxin $\mathrm{B}_{1}$. J. Dairy Sci. 92:3959-3963.

Linsell, C. A., and F. G. Peers. 1977. Aflatoxin and liver cell cancer Trans. R. Soc. Trop. Med. Hyg. 71:471-473.

Marroquín-Cardona, A., Y. Deng, J. Garcia-Mazcorro, N. M. Johnson, N. Mitchell, L. Tang, A. Robinson II, J. Taylor, J. S. Wang, and T. D. Phillips. 2011. Characterization and safety of uniform particle size NovaSil clay as a potential aflatoxin enterosorbent. Appl. Clay Sci. 54:248-257.

Nabney, J., and B. F. Nesbitt. 1965. A spectrophotometric method for determining the aflatoxins. Analyst (Lond.) 90:155-160.

Ndaw, S., M. Bergaentzle, D. Aoude-Werner, and C. Hasselmann. 2000. Extraction procedures for the liquid chromatographic determination of thiamin, riboflavin and vitamin B6 in foodstuffs. Food Chem. 71:129-138.

Peers, F., X. Bosch, J. Kaldor, A. Linsell, and M. Pluijmen. 1987. Aflatoxin exposure, hepatitis B virus infection and liver cancer in Swaziland. Int. J. Cancer 39:545-553.

Phillips, T. D., E. Afriyie-Gyawu, J. Williams, H. Huebner, N. A. Ankrah, D. Ofori-Adjei, P. Jolly, N. Johnson, J. Taylor, A. Marroquin-Cardona, L. Xu, L. Tang, and J. S. Wang. 2008. Reducing human exposure to aflatoxin through the use of clay: A review. Food Addit. Contam. Part A Chem. Anal. Control Expo. Risk Assess. 25:134-145.

Phillips, T. D., L. F. Kubena, R. B. Harvey, D. R. Tayloer, and N. D. Heidelbaugh. 1988. Hydrated sodium calcium aluminosilicate: A high affinity sorbent for aflatoxin. Poult. Sci. 67:243-247.

Phillips, T. D., S. L. Lemke, and P. G. Grant. 2002. Characterization of clay-based enterosorbents for the prevention of aflatoxicosis. Adv. Exp. Med. Biol. 504:157-171.

Poulsen, N. A.. I. Rybicka, L. B. Larsen, A. J. Buitenhuis, and M. K. Larsen. 2015. Short communication: Genetic variation of riboflavin content in bovine milk. J. Dairy Sci. 98:3496-3501.

Queiroz, O. C. M., J. H. Han, C. R. Staples, and T. Adesogan. 2012. Effec of adding a mycotoxin-sequestering agent on milk aflatoxin $\mathrm{M}_{1}$ concentration and the performance and immune response of dairy cattle fed and aflatoxin $\mathrm{B}_{1}$-contaminated diet. J. Dairy Sci. 95:5901-5908.

Shotwell, O. L., C. W. Hesseltine, R. D. Stubblefield, and W. G. Sorenson. 1966. Production of aflatoxin on rice. Appl. Microbiol. 14:425-428.

Smith, E. E., T. D. Phillips, J. A. Ellis, R. B. Harvey, L. F. Kubena, J. Thompson, and G. Newton. 1994. Dietary hydrated sodium calcium aluminosilicate reduction of aflatoxin M1 residue in dairy goat milk and effects on milk production and components. J. Anim. Sci. 72:677-682

Van Soest, P. J., J. B. Robertson, and B. A. Lewis. 1991. Methods for dietary fiber, neutral detergent fiber, and nonstarch polysaccharides in relation to animal nutrition. J. Dairy Sci. 74:3583-3597.

West, S., R. D. Wyatt, and P. B. Hamilton. 1973. Improved yield of aflatoxin by incremental increases of temperature. Appl. Microbiol. 25:1018-1019.

Wildman, E. E., G. M. Jones, P. E. Wagner, R. L. Boman, H. F Troutt, and T. N. Lesch. 1982. A dairy cow body condition scoring system and its relationship to selected production characteristics. J. Dairy Sci. 65:495-501.

Wiseman, H. G., W. C. Jacobson, and W. C. Harmeyer. 1967. Note on removal of pigments from chloroform extracts of aflatoxin cultures with copper carbonate. J. Assoc. Off. Agric. Chem. 50:982-983.

Xiong, J. L., Y. M. Wang, T. D. Nennich, Y. Li, and J. X. Liu. 2015 Transfer of dietary aflatoxin $\mathrm{B}_{1}$ to milk aflatoxin $\mathrm{M}_{1}$ and effect of inclusion of adsorbent in the diet of dairy cows. J. Dairy Sci. 98:2545-2554 